\title{
Ocorrência de acidentes provocados por Lonomia obliqua Walker, no Estado do Paraná, no período de 1989 a 2001
}

\author{
Occurrence of accidents caused by Lonomia obliqua Walker, \\ in the State of Paraná between 1989 and 2001
}

\author{
Claudia Moreira Garcia ${ }^{1}$ e Inês Moresco Danni-Oliveira ${ }^{2}$
}

\begin{abstract}
RESUMO
o presente artigo objetivou mostrar a distribuição dos acidentes com a lagarta Lonomia obliqua, Walker, 1855 no período de 1989 -2001 no Estado do Paraná. Os dados foram obtidos junto a Secretaria de Saúde Ambiental do Paraná. As informações coletadas foram mapeadas utilizando-se o programa Arcview, sendo gerados mapas de ocorrência sazonal de acidentes. Esta sazonalidade foi correlacionada com o ciclo de vida do inseto, que indicou o período de verão como o de maior incidência de acidentes, e ocorrendo as maiores concentrações nas regiões centro-sul, sudeste e sudoeste do Estado.
\end{abstract}

Palavras-chaves: Lonomia obliqua Walker. Sazonalidade. Acidentes. Envenenamento. Animal peçonhento.

\section{ABSTRACT}

The present article aimed to show the distribution of accidents involving the caterpillar Lonomia obliqua, Walker, 1855, in the State of Paraná between 1989 and 2001. The data were obtained from the Environmental Health Department of Paraná. The information collected was mapped using the Arcview program, and maps of the seasonal occurrence of accidents were generated. This seasonality was correlated with the insect's life cycle and summer was shown to be the period with greatest incidence of accidents. The greatest concentrations occurred in the central-southern, southeastern and southwestern regions of the State.

Key-words: Lonomia obliqua Walker. Seasonality. Accidents. Poisoning. Venomous animal.

Responsável por graves acidentes hemorrágicos em Estados do Sul do país, a lagarta do gênero Lonomia obliqua Walker, é um lepidóptero da família Saturniidae, pertencente à subfamília exclusivamente americana dos Hemileucinae. Esta mariposa em seu estado larval, através de suas cerdas urticantes, libera uma toxina com propriedades anticoagulantes, que ao contato com a pele pode ocasionar desta irritação local a hemorragias subcutâneas chegando a hemorragias mais graves que atingem órgãos vitais. A substância de ação fribrinolítica presente nas cerdas das larvas, são registradas em apenas duas espécies do gênero Lonomia: a obliqua e achelous ${ }^{3}$.

0 gênero Lonomia obliqua é reconhecida como parasita do Araticum (Rollinia emarginata), do Cedro (Cedrella fissilis) e do Ipê (Tebula pulcherrima), mas parece haver se adaptado a árvores frutíferas das regiões de ocorrência, como os pessegueiros, abacateiros, ameixeiras e outros 5 .
Os primeiros registros dando conta de acidentes com lagartas de lepidópteros no Brasil foi descrito por Zoroastro Alvarenga ${ }^{6}$ em 1912, mas só a partir de 1967 é que se intensificam os estudos sobre este inseto. Com o aumento no número de casos de acidentes o tema ganha espaço nas pesquisas cientificas no país.

Vários trabalhos foram realizados no Brasil, destacam-se os trabalhos de Lorini ${ }^{3}$ que levou em consideração aspectos biológicos e morfológicos da lagarta e o de Moraes ${ }^{6}$ identificando seus inimigos naturais e levantando as possíveis causas do aumento de sua população.

0 ano de 1989 tornou-se referência na área de saúde pública não só no Paraná como em todos os Estados do Sul do Brasil, em razão do número crescente de acidentes envolvendo este tipo de lepidóptero.

No Rio Grande do Sul, entre os anos de 1989 a 2001, ocorreram 3.331 registros entre acidentes e relatos dos insetos, tendo ocorrido 10 óbitos. Em Santa Catarina ocorreram 2.060

\footnotetext{
1. Setor de Ciências da Terra, Departamento de Geografia, Universidade Federal do Paraná, Curitiba, PR. 2. Setor de Ciências da Terra, Disciplina Climatologia, Departamento de Geografia, Universidade Federal do Paraná, Curitiba, PR.

Endereço para correspondência: Dr ${ }^{\mathrm{a}}$ Inês Noresco Danni-Oliveira. Departamento de Geografia/UFPR. Av. Cel Francisco H. dos Santos s/n. Centro Politécnico, Jardim das Américas, 81532-980 Curitiba, PR.

Tel: 5541 3361-3450, Fax: 5541 3361-3244.

e-mail: inesmdo@ufpr.br

Recebido para publicação em 29/12/2005

Aceito em 8/2/2007
} 
relatos e acidentes, com 6 óbitos. Estes dados fizeram com que estes Estados considerassem a gravidade e freqüência destes acidentes, tomando determinadas providencias, como a padronização de condutas de diagnósticos, monitoramento e capacitação de profissionais.

No Paraná, a lagarta Lonomia obliqua Walker assumiu proporções significativas, o que resultou em um trabalho efetivo de monitoramento e controle dos acidentes pela SESA - Secretaria de Estado da Saúde do Paraná nos municípios de ocorrência.

Os dados de ocorrência de acidentes com a lagarta Lonomia obliqua, foram obtidos junto a Secretaria de Estado da Saúde do Paraná, através de seu Banco de Dados informatizado, que recolhe informações sobre a incidência de ocorrências e acidentes através das Regionais de Saúde do Estado.

Estes registros apresentam informações sobre o número de acidentes, o local de ocorrência (área urbana ou rural), a faixa etária, tipo de vegetação, hora das ocorrências, Municípios, data (dia, mês e ano) e área do corpo atingida. Os dados constantes neste Banco correspondem ao período de 1994 a 2001, sendo o mesmo organizado tomando-se por base os municípios e 0 número de acidentes. Os dados foram plotados em tabelas e em seguida mapeados com o emprego do programa Arcview, gerando mapas de sazonalidade de ocorrência de acidentes.

Para avaliação da sazonalidade da lagarta no Estado do Paraná, levou-se em consideração apenas a fonte de dados dos 242 casos registrados e presentes no EpiInfo, versão 6.04 $\left(\mathrm{CDC} / \mathrm{WHO}^{1}\right)$, cedidos pela SESA (Secretaria de Estado da Saúde do Paraná) e pesquisados por Rubio ${ }^{7}$. Deve se ressaltar que além destes 242 casos, existem mais dez casos relatados entre os anos de 1989 e 1993, mas que em função da informatização ter ocorrido apenas depois de 1994, estes dados não entraram no levantamento efetuado com o EpiInfo, ficando arquivados em fichas epidemiológicas da entidade.
A partir de dados inseridos e levantados por Rubio ${ }^{7}$ procurouse estabelecer uma correlação entre os meses de ocorrência de acidentes, com o ciclo de vida do inseto, além de estabelecer períodos de maior ocorrência. Como base para estabelecer o ciclo de vida do inseto utilizou-se o descrito nos estudos de Lorini ${ }^{3}$.

Panorama da Lonomia obliqua, Walker, 1855 no Estado do Paraná, no período de 1989 a 2001. Com a mobilização da Secretaria de saúde em relação ao constante aumento do numero de acidentes com a lagarta, Rubio ${ }^{7}$, fez um mapeamento geral da situação da Lonomia no Estado do Paraná. Este levantamento efetuado através de fichas epidemiológicas, foi realizado em 22 Regionais de Saúde do Estado e três Centros de Informação/controle de Intoxicações.

Em seu levantamento, Rubio identificou a Lonomia obliqua em várias regiões do Estado (norte, centro, sul, sudoeste, oeste, leste), com predominância nas regiões centro-sul, sudoeste e sudeste. A partir destes dados, observou-se que a lagarta apresenta uma sazonalidade, sendo que a concentração de acidentes e registros, ocorreram nos meses de fevereiro e março (Figura 1).

Outros aspectos apontados em seu trabalho mostram que no Estado as crianças e os trabalhadores estão na faixa de risco de susceptibilidade aos acidentes, uma vez que a maioria dos acidentes ocorreu na área rural, próxima a residências e em locais de trabalho, os membros superiores são os mais atingidos e a identificação correta da vegetação em que os insetos estavam foi pouco definidos, já que nos relatos poucos lembraram do tipo de vegetação.

Distribuição Anual e Sazonal dos Acidentes com a Lagarta Lonomia obliqua Walker, 1855. De 1989 a 2001 foram contabilizados no Estado do Paraná 252 casos, com cinco óbitos (Figura 2). Estes óbitos ocorreram nos municípios de Cruz Machado (1995), Palmital, Tamarana e Virmond (1997) e Vitorino (1998).

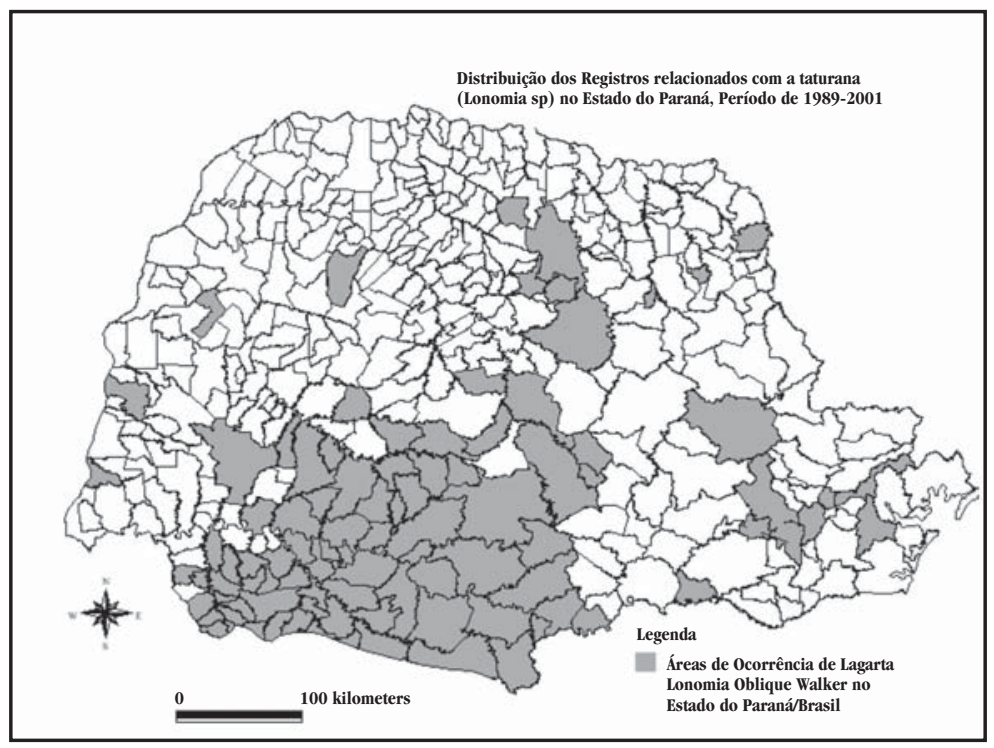

Figura 1 - Áreas de Ocorrência da Lonomia obliqua Walker, no Paraná - Período 19892001. 


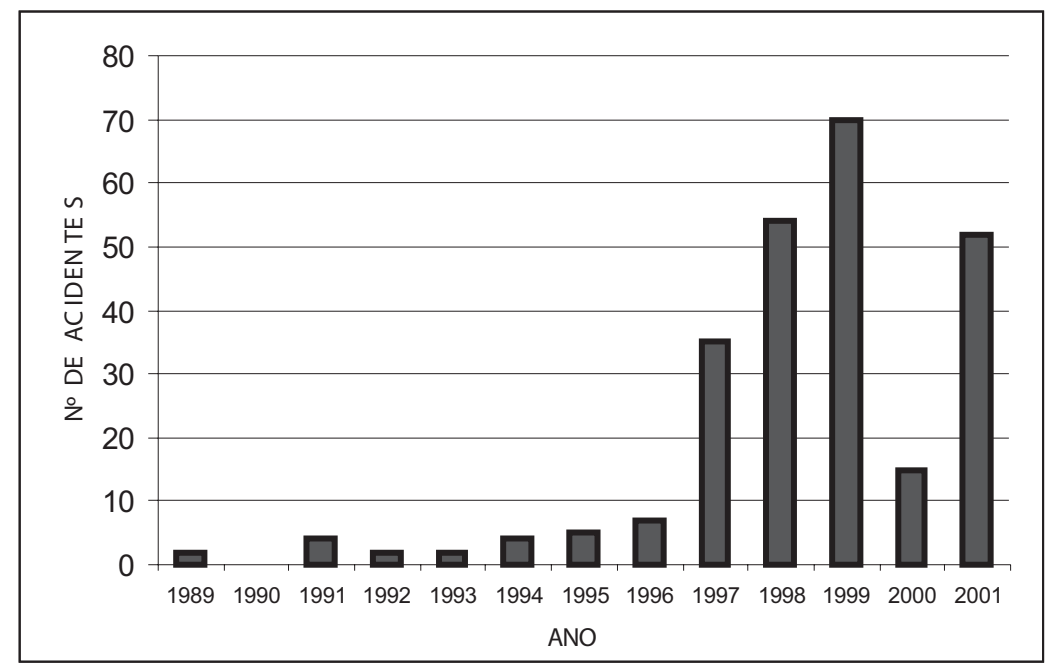

Figura 2 - Número de Acidentes por Contato com a Lonomia obliqua Walker no período 1989 2001.

Os dados apontam (Figura 2) uma evolução no numero de acidentes, que passou a ter um incremento a partir de 1997, alcançando seu máximo do período no ano de 1999. № ano de 2000 ocorreu uma redução acentuada no número de casos devido a fatores que ainda estão em investigação, podendo estar relacionados a variações climáticas, crescimento urbano, aumento da população e a própria atuação da Secretaria do Estado da Saúde do Paraná.

A Figura 3 mostrou que há sazonalidade do ciclo de vida da lagarta e a incidência de acidentes com a mesma. No gráfico fica claro que os períodos de maior ocorrência de acidentes se dá na primavera e no verão, períodos que correspondem à fase de lagarta do inseto. No outono ocorreu uma redução no número de acidentes sendo praticamente nulo no inverno. Exceção se faz ao município de Tamarana que apresentou um caso.

Observou-se que no mês de agosto devem ocorrer as posturas dos ovos pelos indivíduos adultos (mariposas), que em função de seu período de incubação podem eclodir neste mesmo mês, transformando-se me lagartas, forma em que permanecem até maio, abrangendo, portanto, a primavera, todo o verão e 0 inicio do outono, sendo esta a fase mais longa da vida da lagarta. A fase pupal esta vinculada aos meses de junho, julho e possivelmente agosto.

A sazonalidade da distribuição das ocorrências de acidentes no Estado do Paraná é apresentada na Figura 4, que indicou o verão como período de maior número de municípios atingidos pela lagarta, totalizando 39 municípios, onde a maior concentração ocorreu nas macrorregiões do centro-sul, sudeste e sudoeste do estado.

Estas regiões compõem segundo $\mathrm{Maack}^{4}$, o segundo e 0 terceiro planalto paranaense, com altitudes variadas, acompanhando a bacia hidrográfica do Rio Iguaçu. Seu clima, segundo a classificação de Köppen, é do tipo Cfa, isto é, climas mesotérmicos de verão quente e $\mathrm{Cfb}$ climas mesotérmicos de verão brando. Os solos destas regiões apresentam-se de forma variada, mas com predominância do latossolo vermelho eutroférrico típico ou a chamada terra roxa de alta fertilidade.

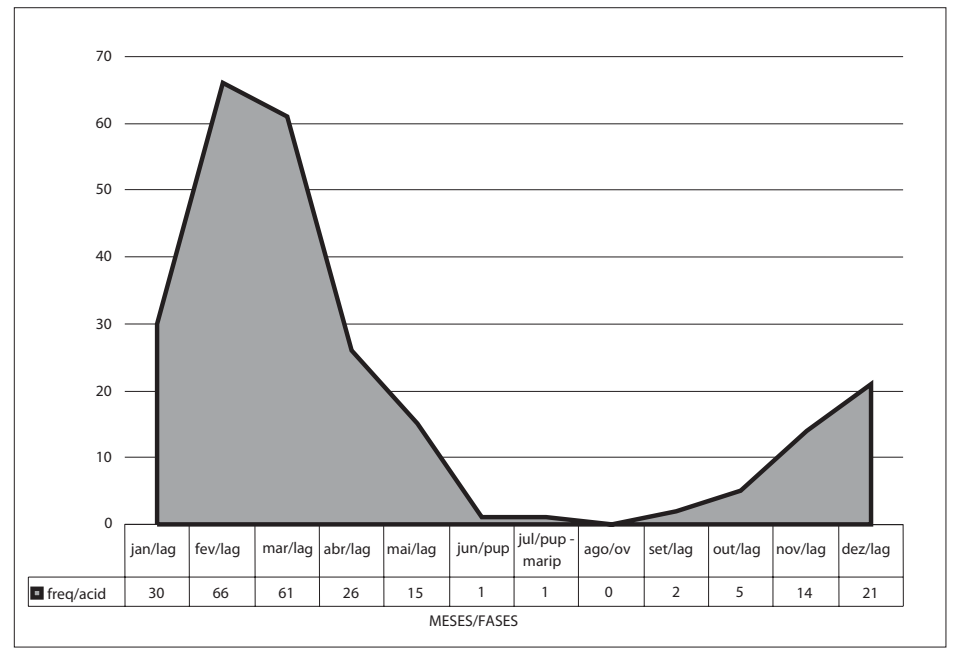

Figura 3 - Freqüiência de acidentes de acordo com o ciclo de vida da lagarta Lonomia obliqua, Walker (1989-2001). 

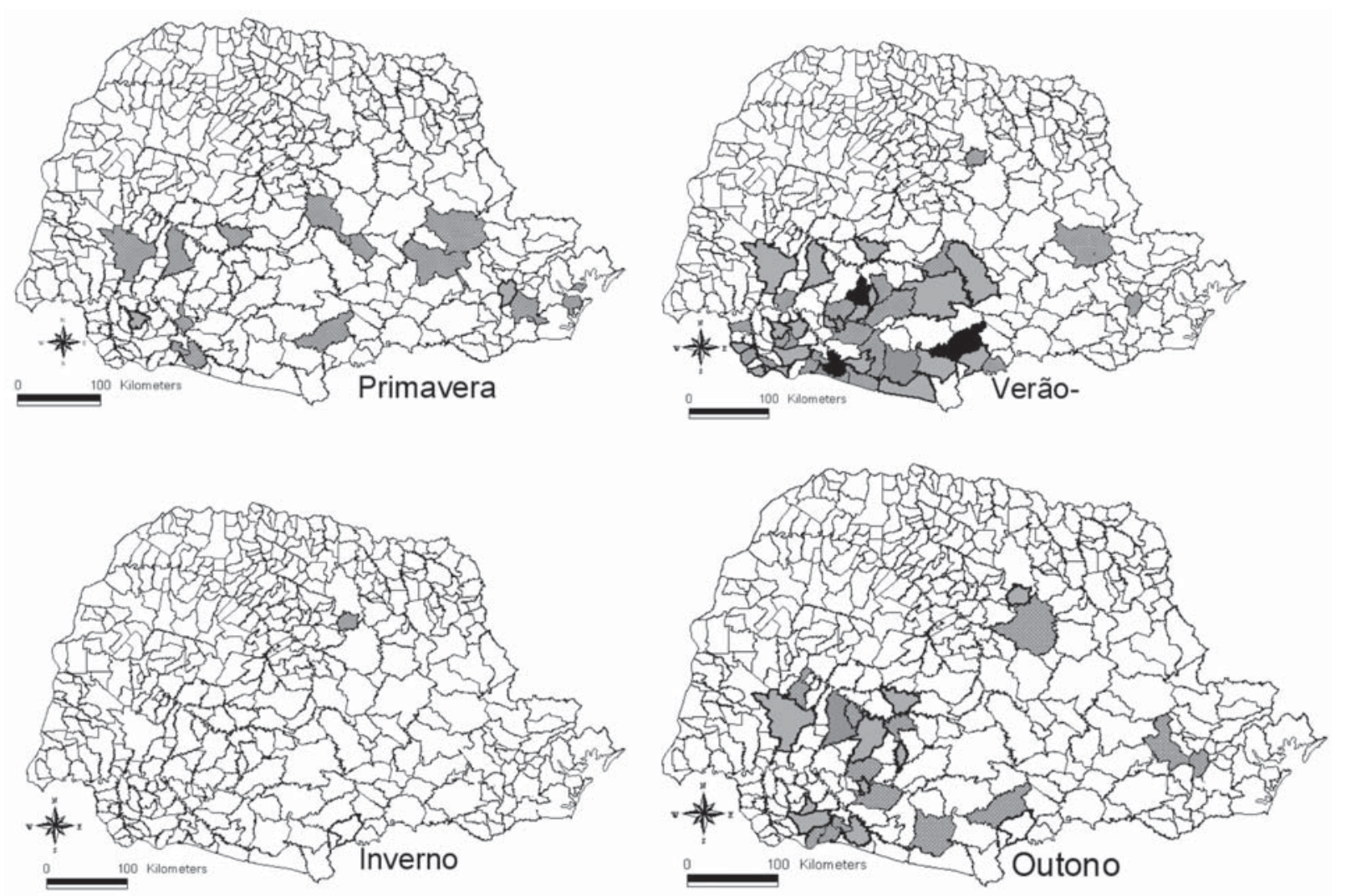

LEGENDA

1 acidente

2 a 5 acidentes

6 a 10 acidentes

Acima de 10 acidentes
Fonte: Base Cartográfica - ANA

Dados Lonomia - SESA

Org. Claudia Moreira Garcia

Figura 4 - Sazonalidade dos acidentes com a lagarta Lonomia obliqua Walker, 1855. Período 1994-2001.

Alguns municípios fogem destas características por estarem situados em regiões diversas, como o norte do Estado com os municípios de Tamarana, Londrina, Carlópolis, Pinhalão e Rolândia, o primeiro planalto com os municípios de Curitiba, Colombo, Campina Grande do Sul, Araucária e Campo Largo, a área da Serra do Mar com o município de Morretes e no litoral com Paranaguá, ocorrência ainda investigada e considerada um fato inusitado, já que foge as características de distribuição geográfica apontada por Lemaire ${ }^{2}$. Os casos registrados nestes municípios são em pequeno número se comparados a grande mancha representada pelas regiões centro-sul, sudeste e sudoeste.

No outono 22 municípios apresentaram registros de acidentes, com predomínio na região centro-sul. Há uma certa continuidade da situação do verão no outono, havendo municípios que apresentaram acidentes nos dois períodos. No inverno, que corresponderia ao período pupal do inseto, observaram-se ocorrências em dois municípios: Tamarana e Santa Lúcia. No município de Tamarana houve um óbito. Estes dois casos foram considerados atípicos para o período.

$\mathrm{Na}$ primavera, houve ocorrências em 15 municípios, este período corresponde ao da eclosão das lagartas, segundo o levantamento feito.

Observou-se que a sazonalidade da lagarta Lonomia obliqua, esta diretamente relacionada com seu ciclo de vida. Este fato demonstra, que os períodos de primavera e verão são os mais perigosos para ocorrência de acidentes e que as regiões centrosul, sudeste e sudoeste são as mais representativas neste tipo de acontecimento. Deve-se observar também, que nestas estações a pessoas usam roupas mais leves, sem mangas, saias e shorts, expondo áreas do corpo suscetíveis aos contatos.

Outro fato a ser considerado é reincidência de acidentes na mesma região ou município, excluindo-se aqui o inverno, onde as ocorrências foram consideradas atípicas. 
Municípios como Cruz Machado, Pato Branco e Laranjeiras do Sul, campeões em registro de acidentes, devem ser constantemente monitorados, além de serem implantadas medidas preventivas locais (campanhas, manuais, etc).

Medidas devem ser tomadas pela Secretaria de Estado da Saúde do Paraná, para prevenção de acidentes. Postos de informações, trabalhos direcionados com a comunidade devem estar sendo feito constantemente.

Os órgãos competentes devem estar atentos ao fato que este aumento gradual no número de acidentes podem estar relacionados com fatores externos (clima, urbanização, crescimento populacional), que podem estar interferindo no ciclo de vida do inseto, incrementando-o. A identificação destes fatores torna-se de vital importância, visto que, através desta informação pode-se tomar providencias para redução destes eventos.

\section{REFERÊNCIAS}

1. Centers for Disease Control and Prevention/WHO (World health Organization), 1996. Epi Info 6. Version 6.04. A Word Processing. Database, and Statistics program for Public Health. Atlanta:CDC/Geneva:WHO, apud Rubio, 2001.
2. Lemaire C. Révision du genre Lonomia Walker [Lep. Attacidae]. Annales de la Societé Entomologique de France (N. S.) 8: 767-861, 1972.

3. Lorini LM. Aspectos Biológicos e Morfológicos da Lonomia obliqua Walker,1855, (Lepidóptera: Saturniidae), em laboratório. Dissertação de Mestrado, Pontifícia Universidade Católica do Rio Grande do Sul, Instituto de Biociências, 1997.

4. Maack R. Geografia Física do Estado do Paraná. Banco de Desenvolvimento do Paraná. Curitiba, 1968.

5. Moraes RHP. Lepidópteros Brasileiros de Importância Médica. In: Schvartsman S (ed) Plantas Venenosas e Animais Peçonhentos. [s.n.] Rio de Janeiro, 1992.

6. Moraes RHP. Identificação dos Inimigos Naturais de Lonomia obliqua Walker, 1855 (Lepidóptera: Saturniidae) e possíveis fatos determinantes do aumento de sua população. 2002. Dissertação de Mestrado. Escola Superior "Luiz Queiroz Filho". Piracicaba, 2002.

7. Rubio GBG. Vigilância Epidemológica de Distribuição da Lagarta Lonomia obliqua, Walker, 1855, no Estado do Paraná: Brasil. Cadernos de Saúde Publica, Rio de Janeiro 17: 1036, 2001. 